\title{
The reflex sympathetic dystrophy syndrome in patients who have had a spinal cord injury
}

\author{
Phillippe Gallien, Benoit Nicolas, Sandrine Robineau, Marie-Pierre Lebot and Régine Brissot \\ Department of Physical Medicine and Rehabilitation, Clinique de Rèèucation Fonctionnelle, Centre Hospitalier et \\ Universitaire de Rennes, Hôpital Pontchaillou, 2, rue Henri Le Guilloux, 35033 Rennes cedex, France
}

Patients suffering from a spinal cord injury often present with a pain syndrome. Although the reflex sympathetic syndrome is a common diagnosis in some forms of neurological disease such as patients with a stroke, it is less frequent in those with a spinal lesion. The authors report eight patients with reflex sympathetic dystrophy who had a spinal cord injury. The diagnosis and treatment are discussed along with a review of literature.

Keywords: reflex sympathetic dystrophy; spinal cord injury

\section{Introduction}

Pain is a frequent problem after spinal cord injury (S.C.I.) In a recent study ${ }^{1} 65.5 \%$ of the patients reported had chronic pain. In the study of Frisbie ${ }^{2} 48$ out of 66 patients had also experienced chronic pain. The diagnosis of pain is essential for a successful understanding of the conduction and its treatment. Joint diseases, syringomyelia, and heterotopic ossifications are of well known etiology. Many classifications of pain have been suggested ${ }^{3}$. Cole ${ }^{4}$ proposed five types of pain: root pain, visceral pain, musculoskeletal pain, late pain associated with syringomyelia and phantom body pain. Central pain often occurs in a distinctive dermatomal or nerve root distribution at the zone of injury consisting of burning, stabbing, needles and pins and numbness.

Reflex sympathetic dystrophy (R.S.D.) is associated with a wide variety of precipitating factors and diseases. It is a frequent complication of some neurological conditions such as stroke and peripheral nerve injuries, but also after trauma of the limbs without neurological damage ${ }^{5-7}$. Some idiopathic cases have been described ${ }^{8,9}$. Few SCI patients have been reported, most often it involves the upper limbs in tetraplegia patients.

The diagnostic criteria for R.S.D. have been described by Kozin et al ${ }^{10,11}$. They considered definite R.S.D. to consist of a burning and aching pain, tenderness and vasomotor instability and swelling. In the next stage dystrophic skin changes can appear and the tissues can become indurated, and the skin cold and hyperhidrotic, with livedo reticularis or cyanosis. Eventually, irreversible tissue damage can occur with ankylosis. Roentgenographic studies show patchy or

Correspondence: P Gallien diffuse demineralisation of the affected joints. Scintigraphy demonstrates increased periarticular uptake in the involved extremities. R.S.D. can lead to important functional impairment, especially when the upper limbs are involved.

This report describes 8 SCI patients with R.S.D. The clinical characteristics and the risk factors are studied. The place of roentgenographic and scintigraphy studies for the diagnosis of R.S.D. is discussed. We also consider the place for calcitonine and clomipranine in the treatment of R.S.D. in such patients.

\section{Methods}

\section{Subjects (Table 1)}

All of the patients were admitted to the Rennes University Rehabilitation Center after an acute S.C.I. between May 1992 and March 1994. The ages ranged from 29 to 59 years (median 35). On an average pain commenced seven months after the injury. There were seven men and one women. The etiology of the S.C.I. was a gunshot wound in five cases, a car accident in two cases and a fall in one patient.

Four patients were tetraplegic and four paraplegic. Details of the medullary level are given in Table 1. The severity of the S.C.I. was classified as Frankel A in five patients, $\mathrm{C}$ in two, and $\mathrm{D}$ in one patient.

\section{Pain description (Table 2)}

The pain was localized below the level of the cord lesion, and was unilateral in four patients and bilateral in the others. Trophic changes were noticed in six patients with diffuse swelling, oedema, and abnormal warm skin temperature. These trophic changes preceded the onset 
of pain in only one patient case (no. 7), and followed it in five (no. 1, 2, 3, 6, 8). All these patients reported permanent burning tingling pain with local hyperesthesia. Two patients (no. 4, 5) had no trophic change. Pain was described as just 'like electricity', stabbing, without a trigger zone at the clinical examination. It did not occur in a distinctive dermatomal or nerve root distribution at the zone of the injury.

The lower limbs were involved in six patients and the upper limbs in two.

\section{Results}

Pain diagnosis

Predisposing factors for R.S.D. were found in four patients:

- diabetes in case no. 8;

- fracture of the head of humerus at the same time as the S.C.I. in case no. 7;

- gunshot wound of the femur in case no. 2 at the same time as the S.C.I;

Table 1 Population

\begin{tabular}{lcccccc}
\hline Subject & Age & Sex & Lesions level & Complete/ incomplete & \multicolumn{2}{c}{$\begin{array}{c}\text { Surgical treat- } \\
\text { ment }\end{array}$} \\
\hline 1 & 28 & Male & C7 & Complete & Gunshot & Yes \\
2 & 30 & Male & L2 & Incomplete & Gunshot & No \\
3 & 40 & Female & C8 & Incomplete & Fall & Yes \\
4 & 25 & Male & T8 & Complete & Vehicle accident & Yes \\
5 & 28 & Male & T4 & Complete & Gunshot & No \\
6 & 28 & Male & L1 & Incomplete & Gunshot & No \\
7 & 42 & Male & C7 & Complete & Vehicle accident & Yes \\
8 & 59 & Male & C5 & Complete & & \\
\hline
\end{tabular}

Table 2 Pain characteristics

\begin{tabular}{|c|c|c|c|c|c|c|}
\hline Subject & $\begin{array}{c}\text { Times from injury } \\
\text { (months) }\end{array}$ & Localization & Bilateral unilateral & $\begin{array}{l}\text { Trophic } \\
\text { changes }\end{array}$ & Risk factors & $\begin{array}{c}\text { Osteoporosis } \\
\text { (X-Rays) }\end{array}$ \\
\hline 1 & 2 & hands & bilateral & Yes & & Diffuse \\
\hline 2 & 5 & feet, knees & bilateral & Yes & Gun wound of left femur & Spotty \\
\hline 3 & 1 & foot & unilateral & Yes & & Spotty \\
\hline 4 & 9 & feet, knees & bilateral & No & & Spotty \\
\hline 5 & 16 & foot & unilateral & No & & Diffuse \\
\hline 6 & 11 & foot & unilateral & Yes & fracture of right tibialis & Diffuse \\
\hline 7 & 3 & hand, shoulder & unilateral & Yes & fracture of left shoulder & Diffuse \\
\hline 8 & 8 & feet, knees & bilateral & Yes & diabetes & Spotty \\
\hline
\end{tabular}

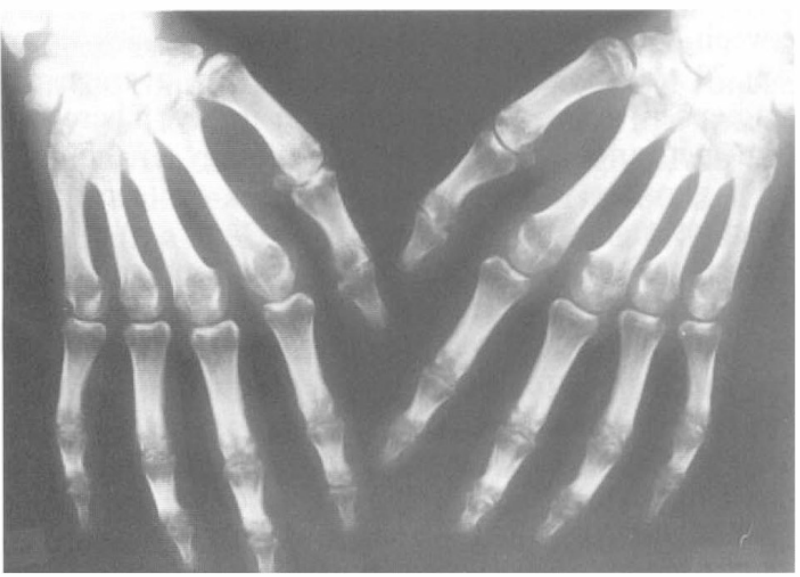

Figure 1 Bilateral diffuse demineralisation of the hands in case no. 1

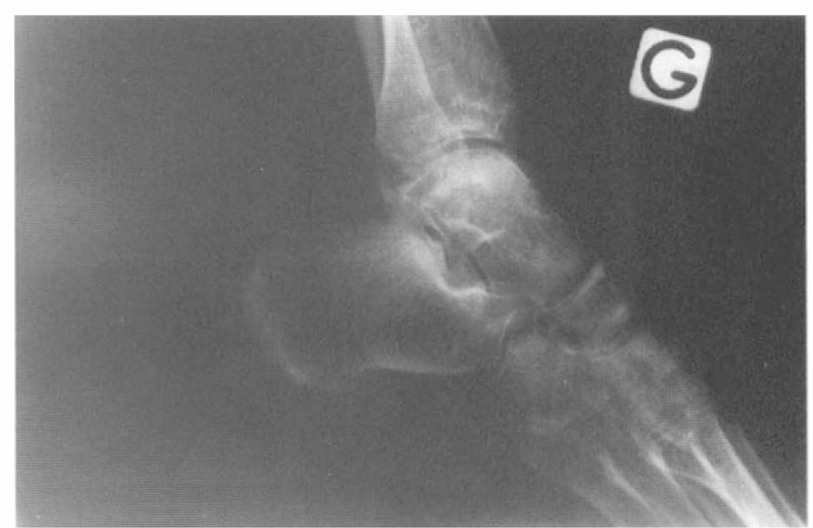

Figure 2 Spotty demineralisation of the left foot in case no. 3 on X-rays 
- fracture of the tibia 1 month before the onset of pain in case no. 6.

A reactive depressive syndrome was always present.

\section{Laboratory and imaging studies}

No abnormalities were found with standard laboratory tests (blood cell counts, erythrocyte sedimentation rate, serum fibrin level, serum and urine electrolyte levels and uric acid serum levels).

Plain roentgenograms of the involved joints demonstrated diffuse osteopenia in four patients (no. $1,5,6,7)$, and a spotty demineralisation in the others (Figures 1 and 2). A three phase technetium bone scan (T.P.B.S.) was always performed. Increased blood flow, blood pool and delayed uptaken images were noticed at the level of the painful joints (Figures 3 and 4).

\section{Treatment and outcome (Table 3)}

In all of the patients, except one (no. 5) the initial treatment, consisted of subcutaneous porcine, 160 international units per days, or salmon calcitonine, 100 I.U. per day, for ten days, then three times a week for 5 weeks. Physiotherapy consisting of alternating immersions in hot and cold water was always included. If no improvement occurred after ten days of treatment the therapeutic modalities were changed. In two patients (no. 3 and 6) pain and

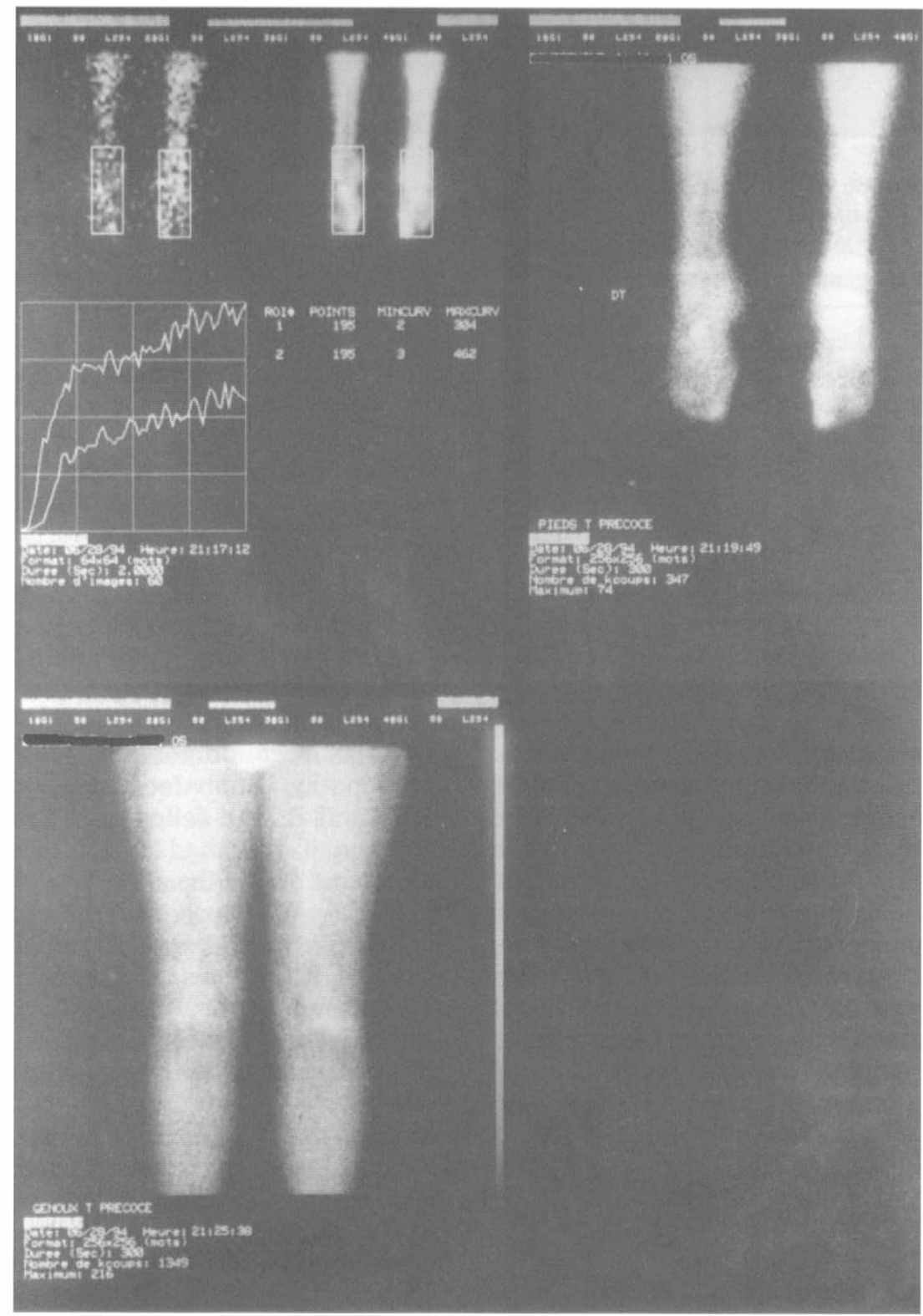

Figure 3 Early vasculo tissular fixation of the right foot in cases no. 6 


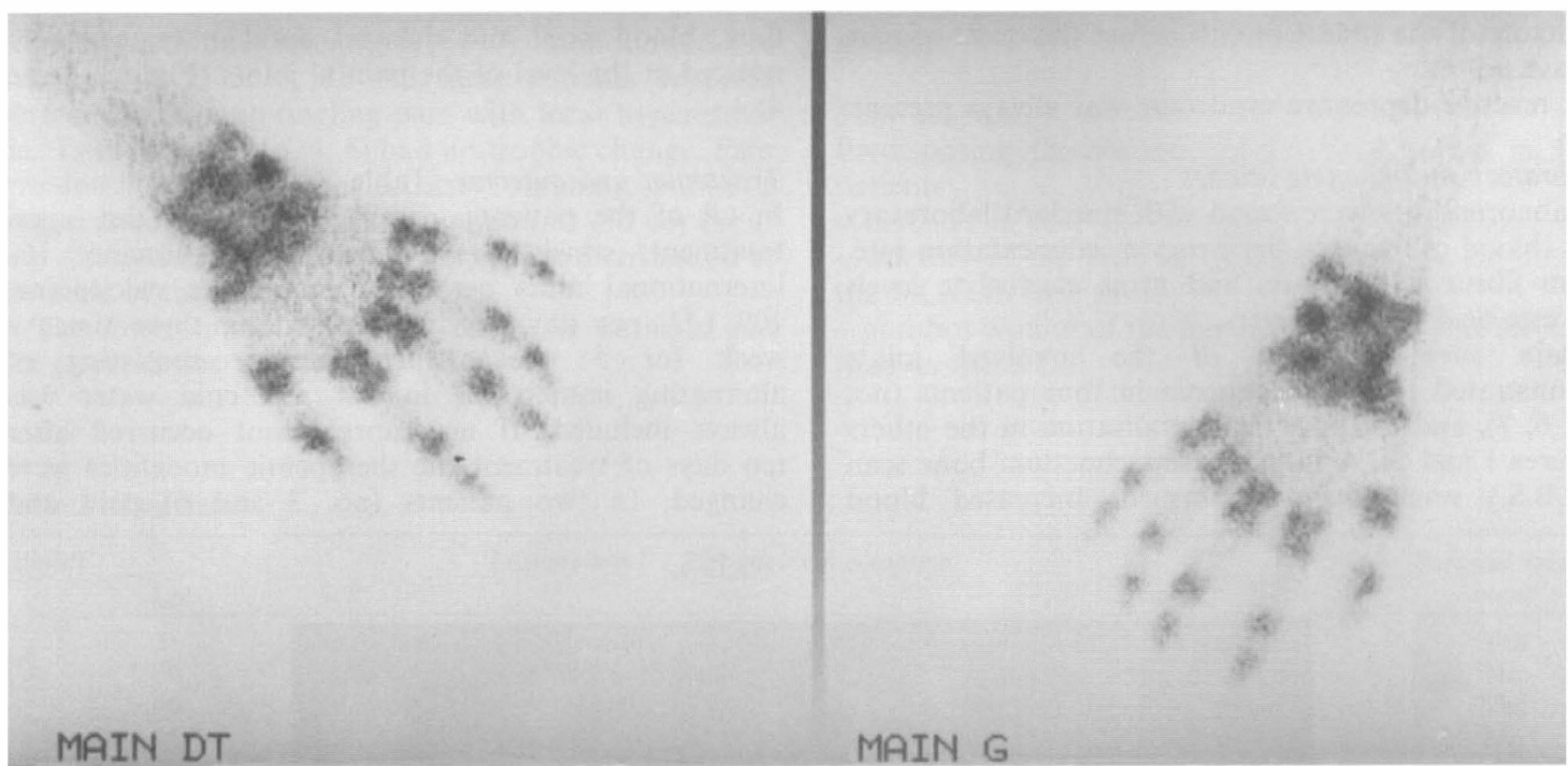

Figure 4 Higher late fixation of both hands in case no. 1

Table 3 Therapeutic management

\begin{tabular}{lcccccc}
\hline Subject & First treatment & Result & Pain modification & Second treatment & Result & Third treatment \\
\hline 1 & calcitonin & good & no & - & & \\
2 & calcitonin & incomplete & yes & carbamazepine & poor & clomipranine \\
3 & calcitonin & incomplete & yes & carbamazepine & good & - \\
4 & calcitonin & poor & no & carbamazepine & poor & clomipranine \\
5 & clomipranine & good & no & - & \\
6 & calcitonin & good & no & clomipranine & good \\
7 & calcitonin & poor & no & carbamazepine & good & - \\
8 & calcitonin & incomplete & yes & & \\
\hline
\end{tabular}

trophic changes improved without any reoccurrence. In patients no. 2, 3 and 8 improvement occurred with disappearance of the trophic changes. We then noticed a change in the description of the pain. There was stabbing pain with paroxysm like electrical discharge. Calcitonin was stopped and carbamazepine introduced, with an improvement in two patients (no. 3, 8). Good results were obtained in the other patients with clomipramine (75 $\mathrm{mg}$ per day). Subject no. 5 was initially treated with clomipranime, because of the absence of trophic changes, with a good result. The mean duration of pain was 153 days $(26 \rightarrow 360)$.

\section{Discussion}

The frequency and risk factors of R.S.D. depend on associated diseases ${ }^{5,9}$. Although pain is a common symptom in S.C.I. patients, reflex sympathetic dystro- phy has been only rarely reported in patients with myelopathy. Subbarao ${ }^{12}$ reported two subjects with unilateral R.S.D. following a neck injury, but did not mention if they had a S.C.I. For Warning ${ }^{13}$ R.S.D. represents $5 \%$ of the etiology of chronic pain syndrome in S.C.I. Wainapel ${ }^{14,15}$ reported two patients with unilateral R.S.D., and Philip ${ }^{16}$ one example of bilateral R.S.D. in tetraplegic patient.

Andrew ${ }^{17}$, Ohry ${ }^{18}$ and Cremer ${ }^{19}$ also described respectively five, four and five examples. All had complete or incomplete tetraplegia. In a recent retrospective study Aisen $^{20}$ found 8 patients with a cervical S.C.I. who presented a R.S.D. according Kozin's criteria. Nineteen patients also had some features of R.S.D. but without the complete syndrome. Bone scans were not obtained. Unlike our report the R.S.D. occurred mainly in the upper limbs. This diagnosis must also be considered in those with a lower limb syndrome. This location is the most frequent in our experience. 
$55 \%$ of the patients had bilateral syndromes: Bilateral involvement of the limbs in R.S.D. is common: in a retrospective study Gougeon ${ }^{21}$ found involvement of both upper limbs in $18 \%$ out of 573 subjects.

R.S.D. has occurred quite soon after S.C.I. Cremer $^{19}$ Philip $^{16}$ and Wainapel ${ }^{14,15}$ observed it within 3 months following injury.

Risk factors are well known in R.S.D. ${ }^{5,9}$, diabetes was found in one subject. All of our patients had a depression syndrome. In cases no. 6 R.S.D. was probably secondary to the limb trauma which he had sustained 11 months after the S.C.I. Subjects no. 2 and no. 7 also presented with limb trauma at the same time as the S.C.I. Gunshot wounds were a frequent cause of the S.C.I.: in 5 patients $(62.5 \%)$. This has been previously noticed: five out of the twelve S.C.I patients reported by Ohry (18), Wainapel ${ }^{14,15}$ Cremer $^{19}$ and Philip ${ }^{16}$ had sustained gunshot wounds, although it only represents $10 \%$ of the etiology of S.C.I. in the literature. ${ }^{22}$ Limb trauma and gunshot wounds are probably two important prediposating factors of R.S.D. in S.C.I.

We noticed two distinctive clinical phases:

- a hot phase with diffuse swelling, vasomotor changes, accompanying or following an onset of burning pain,

- a cold phase: disappearance or absence of trophic changes, then the appearance of a searing stabbing pain without a distinctive dermatomal or nerve root distribution.

In two subjects we observed a cold phase without an initially hot phase, a fact that is now well known. ${ }^{23}$ Cremer ${ }^{19}$ had also described these two kinds of clinical syndrome.

X-rays showed diffuse or spotty demineralisation. Such radiographic abnormalities are also well observed in patients with immobilization osteoporosis which follows S.C.I. Andrew ${ }^{17}$ started spotty demineralisation seemed to be more specific of R.S.D. In our study it happened to be as frequent as was diffuse demineralisation. Roentgenography does not appear to be of great value for the diagnosis of R.S.D. in SCI. Three phase bone scanning is a useful adjunct to diagnosis. Early vasculo tissular fixation is usually higher in the acute phase, However Granier ${ }^{24}$ found that 15 to $25 \%$ of patients had normal or diminished blood flow with an unequivocal clinical diagnosis of R.S.D. A higher late fixation was the only scintigraphic parameter which was always significantly higher whether the R.S.D. was in a hot or in a cold stage.

Spitz ${ }^{25}$ has also reported an accentuation of uptake in immobilization osteoporosis. An early decrease of uptake in the first phase suggested R.S.D. more than osteoporosis in this study. In our survey, scintigraphic abnormalities were only observed in painful areas. If these scintigraphic changes were due to osteoporosis they should have affected all of the skeleton distal to the medullary lesion.
The pathogenesis of R.S.D. remains unclear. Several risk factors have been reported: such as diabetes, dyslipemia and anxiety. R.S.D. is frequently associated with traumatic pathology, but is also seen in such neurological diseases as stroke. In three patients there was an associated fracture which certainly furthered the R.S.D. Davidoff ${ }^{19}$ has stressed the importance of penetrating gun wounds of the spinal cord in the pathogenesis of dysesthetic pain. Five subjects in our study has also sustained gunshot wounds as did two out of five in Cremer's study, and three out of four in the report of Ohry ${ }^{18,19}$. Multiple treatment choices and modalities have been described. Early treatment to prevent morbidity is important. We had good results with calcitonine in the hot phase. The efficacity of calcitonine in R.S.D. is well known ${ }^{18}$. However, it does not appear a good indication in the cold phase. Clomipramine in a dosage of $75 \mathrm{mg}$ per day induced significant improvement when used, although some authors believe that it is a secondary treatment for R.S.D. ${ }^{26}$

Clomipramine possesses specific analgesic properties, and its efficiency has been demonstrated in the treatment of chronic pain. ${ }^{27} \mathrm{We}$ think that this treatment is of great interest in R.S.D. especially in the cold phase. Carbamazepine may also improve R.S.D. in this stage.

We have never used oral or local corticosteroids. Philip $^{16}$ and Cremer $^{19}$ reported improvement or symptoms with systemic corticosteroids. For Wainapel intravenous corticosteroids in the acute phase of spinal cord injury could have a prophylactic effect regarding R.S.D. Only three of our patients have received such a treatment at the time of injury.

R.S.D. is an unfrequent cause of pain in S.C.I. patients. This diagnosis identifies a treatable etiology of a pain syndrome, and must be systematically considered as possible cause of a pain syndrome in a patient with S.C.I. Two phases can be distinguished: a hot phase with trophic troubles, and a cold phase which slightly differs from dysesthesic central pain by its clinical characteristics.

The three phases technetium bone scan is a useful adjunct to diagnosis, particularly in the cold phase. Medullary gunshot wound and associated limb trauma are certainly risk factors for R.S.D.

Calcitonin, in the hot phase, and clomipramine give good results. Calcitonin appears to be a better indication in the hot phase, although clomipramine is useful in the cold phase.

\section{Acknowledgements}

We acknowledge Professor Pierre Pain for his great help with this report. 


\section{References}

1 Fenollosa P, Pallares J, Cervera J, Pelegrin F, Inigo V, Giner M, Forner V. Chronic pain in the spinal cord injured: statistical approach and pharmacological treatment. Paraplegia 1993; 31: $722-729$

2 Frisbie JH, Aguilera EJ. Chronic pain after spinal cord injury: an expedient diagnostic approach. Paraplegia 1991; 128: 460 - 465.

3 Donovan WH, Dimitrijevic MR, Dahm L, Dimitrijevic M. Neurophysiological approaches to chronic pain following spinal cord injury. Paraplegia 1982; 20: $135-146$

4 Cole JD., Illis LS., Sedgwick EM. Intractable central pain in spinal cord injury is not relieved by spinal cord stimulation. Paraplegia 1991; 29: 167-172.

5 Davis SW., Petrillo CR., Eichberg RD., Chu DS. Schoulder hand syndrome in a hemiplegic population a 5-year retrospective study. Arch Phys Med Rehabil 1977; 58: 353-356.

6 Swartzman RJ., Mclellan TL.Reflex sympathetic dystrophy. A review. Arch Neurol 1987; 44: 555-561.

7 Teasell RW., Potter P., Moulin D. Reflex sympathtic dystrophy involving three limbs: a case study. Arch Phys Med Rehabil 1994; 75: $1008-1010$

8 Steinbrocker O., Argyros TG. The schoulder syndrome: present status as a diagnostic and therapeutic entity. Med Clin North Am 1958; 42: 1533 - 1553

9 Doury P. Les algodystrophies: étiologie, particularités cliniques et évolutives selon l'étiologie Sem Hop Paris 1994; 70: 996- 1004.

10 Kozin F., McCarty DJ., Sims JE., Genant HK. The reflex sympathetic dystrophy syndrome. I. Clinical and histologic studies: evidence of bilaterality, accentuation of periarticular regions and predictable response to corticosteroids. $\mathrm{Am} \mathrm{J} \mathrm{Med}$ 1976; 60: $321-331$.

11 Kozin F., McCarty DJ., Sims JE., Genant HK. The reflex sympathetic dystrophy syndrome. II roentgenographic and scintigraphic evidence of bilaterality accentuation of periarticular accentuation . Am J Med 1976; 60: $332-338$

12 Subbarao J. Stillwaelle Reflex sympathetic dystrophy syndrome of the upper extremity: analysis of total outcome of management of 125 cases . Arch Phys Med Rehabil. 1981; 62: 549-554.

13 Waring WP, Maynard F.M. Shoulder pain in acute traumatic quadriplegia. Paraplegia 1991; 29: 37-42.

14 Wainapel SF. Reflex sympathetic dystrophy following traumatic myelopathy. Pain 1984; 18: $345-349$.
15 Wainapel SF, Freed MM. Reflex sympathetic dystrophy in quadriplegia: case report. Arch Phys Med Rehabil 1984; 65: $35-$ 36.

16 Philip PA, Philip A, Mong TN. Reflex sympathetic dystrophy in central cord syndrome: case report and review of literature. Paraplegia 1990; 28: $48-54$.

17 Andrews LG, Armitage KJ. Sudeck's atrophy in traumatic quadriplegia . Paraplegia 1971; 9: $159-165$.

18 Ohry A, Brooks ME, Steinbach TV, Rozin R. Shoulder complications as a cause of delay in rehabilitation of spinal cord injured patients. Paraplegia 1978; 16: $310-316$.

19 Cremer SA, Maynard F, Davidoff G. The reflex sympathetic dystrophy syndrome associated with traumatic myelopathy: report of 5 cases . Pain 1989; 37: 187- 192.

20 Aisen PS., Aisen ML. Shoulder-hand syndrome in cervical spinal cord injury. Paraplegia 1994; 32: 588- 592.

21 Gougeon J., Eschard JP, Moreau Hottin J, Francon J, David Chausse J, Doury P. Les algodystrophies: évolution, formes polyarticulaires, formes à épisodes multiples. Rev Rhum Mal Ostéo Artic 1982; 49: 809-814.

22 Yelnik A, Dizien O, Cordier C, Held JP. Epidémiologie des paraplégies traumatiques. Queques problèmes méthodologiques. In:Masson (ed). Problèmes en médecine de rééducation . Paris 1990, pp 192-196

23 Doury P. Les algodystrophies à forme froide d'emblée. Sem Hop Paris 1994; 70: $1005-1009$.

24 Granier Ph, Manicourt DH, Pauwels S, Nagant DE Deuxchaines $\mathrm{CH}$, Beckers C. Analyse semi quantitative des données de la scintigraphie osseuse en trois temps dans l'algodystrophie des extrémités. Rev Rhuma 1994; 61: 179-188.

25 Spitz J. Clemenz N, Tittel K, Weigand H. Der einflub der inaktivitätsosteoporose auf die szintigraphische darstellung knöcherner verletzungen in bereich des handgelenks. Nucl Med 1989; 28: $124-128$.

26 Masson Ch., Renier J.C., Bregeon Ch., Audran M. Le traitement des algodystrophies: situation actuel, proposition pour de futurs protocoles. Sem Hop Paris 1994; 70: 1058 - 1064

27 Fouquet B., Chalumeau P., Valat J.P., Etienne T. Lombalgies chroniques: facteurs prédictifs de réponse à la clomipranine In Masson (ed). Les médicaments antalgiques: Paris 1992, pp 121 128. 